\title{
Efeitos do suco de alho (Allium sativum Linn.) sobre nematódeos gastrintestinais de caprinos
}

Effects of garlic juice (Allium sativum Linn.) on gastrintestinal nematodes of goats

\author{
Maria José Moreira Batatinha ${ }^{1}$ Mariana Borges Botura ${ }^{2}$ Monica Mattos dos Santos ${ }^{2}$ \\ Ademilton Silva $^{3}$ Maria das Graças A.R. Almeida ${ }^{3}$ Adelmo Ferreira Santana ${ }^{4}$ \\ Tereza Cristina Borio dos Santos Calmon de Bittencourt ${ }^{1}$ Maria Angela Ornelas de Almeida ${ }^{4}$
} \begin{abstract}
O objetivo deste trabalho foi avaliar os efeitos do
suco de alho sobre nematódeos gastrintestinais de caprinos.
Foram utilizados 20 animais, distribuídos em dois grupos tratados
com o suco de alho, um grupo tratado com ivermectina e um
grupo controle sem tratamento. Os percentuais de redução do
número de ovos e larvas de Strongyloidea foram inferiores a 95\%
para todos os grupos. O tratamento de caprinos com o suco de
alho não foi eficiente no controle de nematódeos gastrintestinais. RESUMO
\end{abstract}

Palavras-chave: Allium sativum, caprino, nematódeos.

\section{ABSTRACT}

The objective of this work was to evaluate the effects of the garlic juice on goat gastrointestinal nematodes. Twenty animals were alocated into two groups and treated with garlic juice. One group was treated with ivermectin and one control group was not treated. The percentage reductions in egg and larvae counts of the Strongyloidea were under $95 \%$ for all groups. The treatment of goats with garlic juice was not an effective control of gastrointestinal nematodes.

Key words: Allium sativum, nematodes, goats.

No Brasil, produtos à base do pó de alho, vêm sendo adicionados à ração animal para o tratamento de nematódeos gastrintestinais de ruminantes (BIANCHIN et al., 1999). A resistência destes nematódeos a vários anti-helmínticos existentes no mercado tem sido descrita por VIEIRA \& CAVALCANTE (1998), o que tem incentivado a procura de métodos alternativos para o controle de parasitos.

Estudos in vitro sobre a atividade antihelmíntica do suco de alho em caprinos revelaram sua alta eficácia sobre larvas do gênero Haemonchus (SANTOS et al., 1999). Baseado neste resultado, o presente trabalho objetivou verificar a resposta desta atividade in vivo em caprinos infectados naturalmente com nematódeos gastrintestinais.

Para a obtenção do suco de alho utilizouse uma amostra única de $37,5 \mathrm{~kg}$, a qual foi descascada manualmente, triturada e, em seguida, prensada em gaze e filtrada em papel de filtro, sendo o filtrado acondicionado em frasco de vidro âmbar, e mantido sob refrigeração até o momento de sua utilização. Padronizou-se a administração de $112,5 \mathrm{ml}$ do suco de alho como volume máximo para o animal de maior peso $(45 \mathrm{~kg})$, e a partir da obtenção da concentração deste suco $(402,3 \mathrm{mg} / \mathrm{ml})$, estabeleceu-se a correspondência do volume administrado à dose equivalente $\left(1 \mathrm{~g} \mathrm{~kg}^{-1}\right)$.

Foram utilizados 20 caprinos adultos, das raças Saanen, Anglo-Nubiana e seus cruzamentos, infectados naturalmente com nematódeos gastrintestinais, mantidos em capril com manejo semiintensivo, e sem nenhum tratamento anti-helmíntico realizado no período de 60 dias antes do início do experimento. Estes animais foram distribuídos em

\footnotetext{
${ }^{1}$ Médico Veterinário, Professor, Doutor, Escola de Medicina Veterinária, Universidade Federal da Bahia (UFBA), Av. Ademar de Barros, n. 500, Ondina, 40170-110, Salvador, Bahia. E-mail: mjmb@ufba.br. Autor para correspondência.

${ }^{2}$ Médico Veterinário, Mestrando, Escola de Medicina Veterinária, UFBA

${ }^{3}$ Médico Veterinário, Escola de Medicina Veterinária, UFBA.

${ }^{4}$ Médico Veterinário, Professor, Mestre, Escola de Medicina Veterinária, UFBA.
} 
quatro grupos experimentais: grupo I, tratado com suco de alho na dose de $1 \mathrm{~g} \mathrm{~kg}^{-1} \mathrm{dia}^{-1}$ durante oito dias; grupo II tratado com a mesma dose durante quatro dias; grupo III tratado com dose única de $0,2 \mathrm{mg} \mathrm{kg}^{-1} \mathrm{de}$ ivermectina, e o grupo IV, controle, não submetido a qualquer tratamento. As fezes foram coletadas semanalmente, diretamente da ampola retal, e as contagens do número de ovos por grama de fezes (OPG) e os cultivos de larvas realizados segundo as técnicas de TAIRA (1980) e UENO \& GONÇALVES (1998) respectivamente, durante os 52 dias de duração do experimento. $\mathrm{O}$ percentual de redução do número de ovos e larvas dos grupos experimentais em relação ao controle foi determinado pelo teste de redução de ovos por grama de fezes segundo VIZARD \& WALLACE (1987) e a análise estatística dos dados com os valores transformados em logaritmo pela equação: $y=\log (x+25)$ (BOX \& COX, 1964) foi realizada através da análise de variância univariada.

Observou-se que, a partir do $10^{\circ}$ dia experimental, ocorreu um aumento do número de ovos e larvas de Strongyloidea (Haemonchus, Oesophagostomum e Trichostrongylus) nos grupos I e II, embora este achado não tenha sido estatisticamente significativo $(\mathrm{p}<0,05)$ entre os diferentes dias. No grupo tratado com ivermectina (grupo III), foi observada uma diminuição significativa no número de ovos (dia 10) e larvas (dias 10, 34 e 52) em relação ao dia zero.

No grupo I, os maiores percentuais de redução do número de ovos e larvas de Strongyloidea foram de $11,84 \%$ e $74,25 \%$ respectivamente, enquanto que os animais do grupo II não responderam ao tratamento. Estes resultados revelam que o tratamento de caprinos com o suco de alho não foi eficaz no controle de nematódeos gastrintestinais, considerandose que a eficácia de um anti-helmíntico é assegurada quando o percentual de redução do número de ovos de nematódeos gastrintestinais é superior a $95 \%$ (HORNER \& BIANCHIM, 1989). Baixa eficácia antihelmíntica foi constatada utilizando-se a dose única de $3 \mathrm{~g} \mathrm{~kg}^{-1}$ de alho sob a forma de suco em caprinos infectados experimentalmente com $\boldsymbol{H}$. contortus (VIEIRA et al.,1999). Redução média de apenas $47,3 \%$ na contagem de OPG em amostras de fezes de bovinos tratados com pó de alho no sal mineral também foi encontrado por BIANCHIN et al. (1999).

A ausência de similaridade entre os resultados de estudos in vitro (SANTOS et al., 1999) com os obtidos neste trabalho in vivo, pode ser resultante, da ação dos microorganismos ruminais sobre os constituintes químicos ativos presentes no alho, reduzindo sua biodisponibilidade, uma vez que, nenhuma referência sobre o metabolismo ruminal destes constituintes tenha sido encontrada. Além disso, as diferenças na composição química entre as diversas preparações farmacêuticas do alho, também podem interferir nas suas propriedades terapêuticas (KASUGA et al., 2001).

Os percentuais de redução de $94,68 \%$ do número de ovos e $89,82 \%$ de larvas observados no grupo III, podem ser um indicativo de resistência dos parasitos à ivermectina, já observado por MELO et al. (1998).

\section{REFERÊNCIAS BIBLIOGRÁFICAS}

BIANCHIN, I. et al. Eficiência do pó de alho (Allium sativum L.) no controle de parasitos de bovinos. Campo Grande : Embrapa Gado de Corte, 1999. 31p. (Boletim Técnico, 8).

BOX, G.E.P.; COX, D.R. An analysis of transformations. J R Stat Soc, v.B26, p.211-243, 1964.

HORNER, M.R.; BIANCHIN, I. Teste para quantificar a resistência de nematódeos contra produtos anti-helmínticos. Campo Grande : EMBRAPA, 1989. 5p. (Comunicado técnico, 32).

KASUGA, S. et al. Pharmacologic activities of aged garlic extract in comparison with other garlic preparations. J Nutr, v.131, n.3, p.1080S-1084S, 2001.

MELO, A.C.F.L et al. Resistência a anti-helmínticos em nematódeos gastrintestinais de ovinos e caprinos no município de Pentecoste, Estado do Ceará. Ciên Anim, v.8, n.1, p.7-11, 1998.

SANTOS, M.; ALMEIDA, M.A.O.; BATATINHA, M.J.M. Avaliação dos efeitos de diferentes extratos do alho (Allium sativum) sobre nematódeos gastrintestinais de caprinos. In: SEMINÁRIO BRASILEIRO DE PARASITOLOGIA VETERINÁRIA, 11., SEMINÁRIO DE PARASITOLOGIA VETERINÁRIADOS PAÍSES DO MERCOSUL, 2., SÍMPOSIO DE CONTROLE INTEGRADO DE PARASITOS DE BOVINOS, 1, 1999, Salvador, BA. Anais... Salvador : CBPV, 1999. p.160.

TAIRA, N. O' ring technique. In: SHIMIZU, T. et al. Buiatrics. Tokio : Kindai, 1980. p.89-90.

UENO, H.; GONÇALVES, P.C. Manual para diagnóstico das helmintoses de ruminantes. 4.ed. Salvador: JICA, 1998. 143p. p. 25-43.

VIEIRA, L.S.; CAVALCANTE, A.C.R. Resistência antihelmíntica em nematódeos gastrintestinais de caprinos. R Bras Med Vet, v.20, n.3, p.112-117, 1998.

VIEIRA, L.S. et al. Evaluation of anthelmintic efficacy of plants available in Ceará State, North-east Brazil, for the control of goat gastrintestinal nematodes. Reveu Méd Vet, v.150, n.5, p.447452, 1999.

VIZARD, A.L.; WALLACA, R.J. A simplified faecal egg count reduction test. Aust Vet J, v. 64, n.4, p.109-111, 1987. 